\title{
Avaliação de Extratos Aquosos de Espécies Vegetais, Aplicados Via Pulverização Foliar, Sobre Meloidogyne javanica.
}

\author{
Cristiane Gonçalves Gardiano ${ }^{1}$, Silamar Ferraz ${ }^{1}$, Everaldo Antônio Lopes ${ }^{1}$, Paulo Afonso Ferreira ${ }^{1}$, Silvia Leão \\ Carvalho $^{1}$, Leandro Grassi de Freitas ${ }^{1}$.
}

${ }^{1}$ Departamento de Fitopatologia, Universidade Federal de Viçosa, CEP 36570-000, Viçosa-MG, Brasil. E-mail: cris_gardiano@ yahoo.com.br Autor para correspondência: Cristiane Gonçalves Gardiano Data de chegada: 14/08/2007. Aceito para publicação em: 30/06/2008

Diversos compostos com potencial nematicida podem ser obtidos a partir de plantas. Entretanto, a aplicação de tais extratos, principalmente na forma de pulverização sobre a parte aérea, vem sendo pouco estudada para o controle deste patógeno. Desta forma, o objetivo do trabalho foi avaliar a atividade nematicida sistêmica dos princípios ativos encontrados em espécies de plantas, via pulverização foliar dos extratos aquosos, sobre Meloidogyne javanica.

$\mathrm{O}$ experimento foi conduzido em casa-de-vegetação, em vasos plásticos, onde foram transplantadas mudas de tomateiro 'Santa Cruz Kada'. O solo foi infestado com 5.000 ovos de M. javanica e, em seguida, os vasos foram protegidos com sacos plásticos e as plântulas de tomateiro foram pulverizadas com água destilada (testemunha) e

Tabela 1. Efeito da pulverização dos extratos aquosos espécies vegetais sobre a altura, a massa fresca da parte aérea, das raízes e o número de galhas e de ovos por sistema radicular de tomateiro, aos 60 dias após a infestação do solo com 5.000 ovos de Meloidogyne javanica.

\begin{tabular}{|c|c|c|c|c|c|c|c|c|}
\hline \multirow{2}{*}{$\begin{array}{l}\text { Tratamentos } \\
\text { Grupo } 1 \\
\text { Testemunha }\end{array}$} & \multirow{2}{*}{$\begin{array}{l}\text { Altura de } \\
\text { plantas (cm) } \\
89,86 \text { b }\end{array}$} & $\begin{array}{l}\text { Massa fresca da } \\
\text { parte aérea }(g)\end{array}$ & \multicolumn{2}{|c|}{$\begin{array}{l}\text { Massa fresca } \\
\text { da raiz }(\mathrm{g})\end{array}$} & \multicolumn{2}{|c|}{$\begin{array}{l}1 \text { de galhas/sistema } \\
\text { radicular }\end{array}$} & \multicolumn{2}{|c|}{$\begin{array}{l}{ }^{1} \text { de ovos / sistema } \\
\text { radicular }\end{array}$} \\
\hline & & 98,34 & 24,29 & $\mathrm{a}$ & 63,58 & $\mathrm{~ns}$ & 54616,93 & ns \\
\hline Manjericão & 85,86 b $\quad(-4,45) *$ & $103,36(+5,10)^{*}$ & 23,34 & a $(-3,95)^{*}$ & 58,35 & $(-8,22)^{*}$ & 48720,44 & $(-10,79)^{*}$ \\
\hline Cidreira & $89,86 \mathrm{~b}$ & $92,75 \quad(-5,68)$ & 17,84 & $\mathrm{~b}(-26,60)$ & 57,77 & $(-9,14)$ & 52465,81 & $(-3,94)$ \\
\hline Carqueja & $91,29 \mathrm{~b} \quad(+1,60)$ & $97,70 \quad(-0,65)$ & 18,40 & b $(-24,25)$ & 60,03 & $(-5,58)$ & 59622,57 & $(+9,16)$ \\
\hline Hortelã & $92,43 \mathrm{~b} \quad(+2,86)$ & $97,95 \quad(-0,39)$ & 20,42 & $\mathrm{~b}(-15,93)$ & 64,30 & $(+1,13)$ & 54793,63 & $(+0,32)$ \\
\hline Bardana & $93,00 \mathrm{~b} \quad(+3,50)$ & $89,14 \quad(-9,35)$ & 18,72 & b $(-22,93)$ & 66,16 & $(+4,06)$ & 59153,02 & $(+8,30)$ \\
\hline Cinamomo & 95,14 a $\quad(+5,87)$ & $97,69 \quad(-0,66)$ & 24,88 & a $(+2,43)$ & 66,33 & $(+4,32)$ & 82855,95 & $(+51,70)$ \\
\hline Melão-de-São-Caetano & 96,40 a $(+7,31)$ & $96,39 \quad(-1,99)$ & 24,46 & a $(+0,69)$ & 71,57 & $(+12,57)$ & 87690,26 & $(+60,55)$ \\
\hline Cavalinha & 98,57 a $(+9,70)$ & $100,47(+2,16)$ & 20,27 & b $(-16,55)$ & 65,22 & $(+19,67)$ & 66681,30 & $(+42,44)$ \\
\hline Artemísia & 100,71 a $(+12,07)$ & $97,57 \quad(-0,78)$ & 17,04 & $\mathrm{~b}(-29,85)$ & 77,18 & $(+21,39)$ & 86302,11 & $(+58,01)$ \\
\hline Calopogônio & 101,43 a $(+12,88)$ & $101,15(+2,86)$ & 17,95 & $\mathrm{~b}(-26,10)$ & 81,15 & $(+27,63)$ & 92163,81 & $(+68,74)$ \\
\hline Mamona & 102,29 a $(+13,83)$ & $102,45(+4,18)$ & 18,79 & $\mathrm{~b}(-22,64)$ & 82,76 & $(+30,17)$ & 84468,60 & $(+54,66)$ \\
\hline Coeficiente de variação (\%) & 10,32 & 12,52 & & 25,96 & 26,59 & & 22,36 & \\
\hline \multicolumn{9}{|l|}{ Grupo 2} \\
\hline Testemunha & $67,08 \mathrm{c}$ & $26,54 \mathrm{c}$ & 17,78 & $\mathrm{~b}$ & $42,65 \mathrm{r}$ & & $2265,39 \mathrm{~b}$ & \\
\hline Guiné & $(+37,78)^{*}$ & 118,00 a $(+344,61)^{*}$ & 26,20 & a $(+47,36)^{*}$ & 16,15 & $(-61,10)^{*}$ & $1699,51 \mathrm{~b}$ & $(-24,98)^{*}$ \\
\hline Girassol & $(+19,75)$ & $79,37 \mathrm{~b}(+199,06)$ & 22,81 & a $(+28,23)$ & $27,46 \mathrm{c}$ & $(-35,62)$ & $2003,93 \mathrm{~b}$ & $(-10,87)$ \\
\hline Guandu & $(+8,45)$ & $29,42 \mathrm{c} \quad(+10,85)$ & 15,50 & $\mathrm{~b} \quad(-12,82)$ & $45,27 \mathrm{~b}$ & $(+6,14)$ & $2192,60 \mathrm{~b}$ & $(-3,21)$ \\
\hline $\mathrm{Nim}$ & $(+4,98)$ & $28,73 \mathrm{c}$ & 16,62 & $(-8,77)$ & $42,97 \mathrm{~b}$ & $(+0,75)$ & $2800,84 \mathrm{a}$ & $(+23,63)$ \\
\hline Mucuna-cinza & $(+4,61)$ & $24,00 \mathrm{c}$ & 14,32 & b $\quad(-19,46)$ & $49,37 \mathrm{~b}$ & $(+15,76)$ & 3608,69 a & $(+59,29)$ \\
\hline Confrei & $(+3,86)$ & $25,86 \mathrm{c}$ & 14,89 & b $\quad(-16,25)$ & 55,08 & $(+29,14)$ & $2806,18 \mathrm{a}$ & $(+23,87)$ \\
\hline Falso-boldo & $(-5,34)$ & $28,27 \mathrm{c}$ & 15,81 & b $\quad(-11,08)$ & $45,19 \mathrm{~b}$ & $(+5,95)$ & $2138,87 \mathrm{~b}$ & $(-5,58)$ \\
\hline Feijão-de-porco & $(-12,16)$ & $27,56 \mathrm{c}$ & 14,50 & b $\quad(-18,50)$ & $43,59 \mathrm{~b}$ & $(+2,20)$ & 3126,49 a & $(+38,01)$ \\
\hline Mentrasto & $(-10,06)$ & 23,85 c $\quad(-10,14)$ & 13,22 & b $\quad(-25,64)$ & $63,09 a$ & $(+47,94)$ & 3242,82 a & $(+43,15)$ \\
\hline Funcho & $(+41,87)$ & 101,23 a $(+281,42)$ & 22,13 & a $(+24,46)$ & $25,41 \mathrm{c}$ & $(-40,42)$ & $2019,05 \mathrm{~b}$ & $(-11,54)$ \\
\hline Coeficiente de variação (\%) & 15,89 & 48,7 & & 7,24 & 26 & 59 & 19 , & \\
\hline
\end{tabular}

Média de 7 repetições. Médias seguidas pela mesma letra, nas colunas, não diferem entre si pelo teste Scott-Knot, a $5 \%$ de probabilidade *Percentual de redução (-) ou acréscimo (+) ao serem comparados os tratamentos com a testemunha só com nematóide. 
com os extratos aquosos obtidos a partir de folhas de artemísia (Chrysanthemum parthenium (L.) Bernh.), bardana (Arctium lappa L.), calopogônio (Calopogonium muconoides), capim-cidreira (Cymbopogon citratus (DC.) Staph), carqueja (Bacharis trimera (Less) D.C.), cavalinha (Equisetum sp.), cinamomo (Melia azedarach L.), hortelã (Mentha sp.), mamona (Ricinus communis L.), manjericão (Ocimum basilicum L.) e melão-de-São Caetano (Momordica charantia L.), falso-boldo (Plectranthus barbatus Andrews), confrei (Symphitum sp.), feijão-de-porco (Canavalia ensiformis (L.) D.C.), funcho (Foeniculum vulgare Mill.), girassol (Helianthus annus L.), guandu (Cajanus cajan (L.) Mill), guiné (Petiveria alliacea L.), mentrasto (Ageratum conyzoides L. Sieber), mucuna-cinza (Mucuna pruriens (L.) D.C.) e nim (Azadirachta indica A. Juss). Essas espécies vegetais foram divididas em dois grupos para avaliação do experimento. Os extratos foram obtidos através da mistura de $1 \mathrm{~g}$ de folhas de cada espécie com $10 \mathrm{~mL}$ de água destilada. Após $24 \mathrm{~h}$ de repouso, a mistura foi filtrada em gaze e os filtrados (extratos) foi colocado em erlemeyers identificados e protegidos da luz com papel alumínio, para serem pulverizados nas plantas em seguida. Os extratos foram aplicados a cada 15 dias, durante um período de 60 dias. O delineamento experimental adotado foi o do tipo inteiramente casualizado, com 12 tratamentos para o grupo 1 e 11 tratamentos para o grupo 2, ambos com sete repetições. Sessenta dias após a inoculação das plantas, os números de ovos e de galhas por sistema radicular, a altura das plantas e a massa fresca do sistema radicular e da parte aérea foram avaliados.

Dentre as espécies avaliadas, as do grupo 1 não apresentaram diferença significativa quanto à diminuição do número de galhas e de ovos. A pulverização dos extratos de algumas plantas aumentou a altura dos tomateiros, quando comparados com a testemunha (Tabela 1). Com relação às plantas do grupo 2 , a pulverização com os extratos de guiné, funcho e girassol, reduziram o número de galhas em $61 \%$, $40,4 \%$ e $35,6 \%$, respectivamente, quando comparados com a testemunha. No entanto, não houve diferença significativa quanto à redução do número de ovos em relação à testemunha. Essas mesmas espécies vegetais proporcionaram aumento na altura e no peso da massa fresca da raiz e da parte aérea das plantas de tomateiro (Tabela1). 